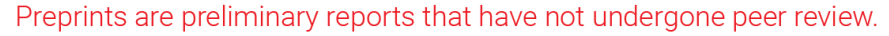 They should not be considered conclusive, used to inform clinical practice, or referenced by the media as validated information. \\ Differentially Evolutionary Pathways and Their Interactions in Genes Expressed in Brain of Human and Macaque
}

\section{Yuequn Ma}

Tianjin Medical University

Changying Cao

Tianjin Medical University

Mengwen Zhao

Tianjin Medical University

Xinhua Liu

Tianjin Medical University

\section{Feng Cheng}

University of South Florida

Ju Wang ( $\square$ wangju@tmu.edu.cn )

Tianjin Medical University https://orcid.org/0000-0002-6514-0923

\section{Research Article}

Keywords: nervous system, brain, pathway evolution, pathway crosstalk

Posted Date: March 15th, 2021

DOI: https://doi.org/10.21203/rs.3.rs-295165/v1

License: (1) This work is licensed under a Creative Commons Attribution 4.0 International License. Read Full License 


\section{Abstract}

As the key organ that separates humans from non-human primates, the brain has continuously evolved to adapt to the changes of environments and climates. Although human shares most genetic, molecular, and cellular features with other primates such as macaques, there are significant differences in the structure and function of the brain between humans and these species. Thus, exploring the differences between the brains of human and non-human primates in the context of evolution will provide insights into the development, functionality, and diseases of the human nervous system. Since the genes involved in many aspects of the human brain are under common pressures of natural selection, their evolutionary features can be analyzed collectively at the pathway-level. In this study, the molecular mechanisms underlying human brain capabilities were explored by comparing the evolutionary features of pathways enriched in genes expressed in the human brain and the macaque brain. 31 differentially expressed evolutionary pathways were identified in the brains of humans and macaques, among which included those related to neurological diseases, signal transduction, immunological response, and metabolic processes. By analyzing differentially expressed genes in brain regions or development stages between humans and macaques, 10 pathways and 4 pathways were found to have evolutionary distinctions, respectively. We further performed crosstalk analysis of pathways in order to obtain an intuitive correlation between the pathways, of which is helpful in understanding the mechanisms of interaction between pathways. Our results shed light on a comprehensive view of the evolutionary pathways of the human nervous system and provide a reference for the study of human brain development.

\section{Introduction}

As the key component that separates human from non-human primates, the brain is responsible for the most sophisticated cognitive functions and behaviors of humans. Similar to other organs, the human brain has changed and evolved over the history of time to adapt to the changes of environments and climates (Sousa, Meyer et al. 2017; Verendeev and Sherwood 2017). Although there are significant differences in the size, structure, and cognitive function between the brains of humans and the brains of other primates, humans share most genetic, molecular and cellular features with these species, and the human mental abilities are believed to have gradually evolved from ancestral forms and functions (Sakai, Hirata et al. 2012). Thus, exploring the differences between the brains of human and non-human primates in the context of evolution will provide insights into the development, function and diseases of human nervous system (Zhu, Sousa et al. 2018).

In the past several years, significant progress has been made in comparative studies on the brain for humans and other species. Some studies mainly focus on the phenotypic similarities and differences between human and non-human brains, such as size, structure, neuron number, and cell types comprising the brain and its associative components. Recent advances in technology for tissue-processing and the availability of larger brain tissue sets, as well as the development of methods in genomic, neuroimaging and other fields, has made it possible to explore the mechanisms underlying human mental capabilities from different levels, which has greatly enhanced our understanding on the genomic, transcriptomic, 
neuroanatomic, and behavioral features of the brain (Sousa, Meyer et al. 2017; Zhu, Sousa et al. 2018; Pollen, Bhaduri et al. 2019). For example, by comparing the brain of human and chimpanzees or other primates, unique features of the human brain with respect to development, cortical organization, connectivity, and aging can been revealed via neuroimaging techniques such as magnetic resonance imaging, positron emission tomography imaging or diffusion-weighted imaging (Rilling 2014; Ardesch, Scholtens et al. 2019). Through the use of a combined comparative neuroimaging and genetic analysis on the cortex region of human and chimpanzee brain, Wei et al. found that evolutionary changes in the human genome may play an important role in the expansion and cortical organization of cognitive functional networks in the human brain, potentially in service of specialization of higher-order cognitive function in human evolution (Wei, de Lange et al. 2019). Sousa et al. performed transcriptome sequencing for 16 regions of human, chimpanzee, and macaque brains, and identified the global, regional, and cell-type-specific gene expression patterns in these species (Sousa, Zhu et al. 2017). These studies have demonstrated the highly divergent and derived features of the human brain, which is correlated with the diverse molecular and cellular features of the organ. However, due to its remarkable complexity, our understanding of how the brain has changed in the human lineage remains incomplete.

In searching for the genomic signals evolutionarily related to the structure and function specificities of human brain, a number of genes have been identified. However, under the pressure of natural selection, the genes related to the same phenotypic trait tend to be affected as a whole because mutation on one gene can cause changes in associated genes or networks (Berg and Coop 2014; Daub, Dupanloup et al. 2015). Thus, these genes should be treated collectively and a pathway-based approach for evolutionary analysis may be a more appropriate choice (Stranger, Stahl et al. 2011; de Juan, Pazos et al. 2013). Actually, pathway-based approach has been used to identify evolutionary features specific to marine mammals (Chikina, Robinson et al. 2016), evolutionarily distinct functional characteristics between sponges and metazoans (Srivastava, Simakov et al. 2010), or adaptive characteristics of people living in different environments (Bergey, Lopez et al. 2018).

In this study, we tried to explore the molecular mechanisms underlying human brain by comparing the evolutionary features of pathways enriched in genes expressed in human brain and macaque brain. Having a nervous system comparable to the one found in humans, macaques are the most commonly studied non-human primates in neuroscience and have also been widely used as an animal model for studying the evolution of human nervous system (Sousa, Meyer et al. 2017; Sousa, Zhu et al. 2017; Muchnik, Lorente-Galdos et al. 2019; Pattabiraman, Muchnik et al. 2020; Yin, Lu et al. 2020). In earlier studies, a large number of genes expressed in human or macaque brains have been identified, which provide valuable information for understanding the molecular features of the human brain and its evolution. By analyzing evolutionary constraints acting on pathways enriched in genes expressed in the brain tissue of human and macaque, we identified the pathways that are under selection pressures in the evolution of the human nervous system.

\section{Materials And Methods}


In this study, we adopted the framework of 2DNS, a modified McDonald-Kreitman test to detect selection pressures on multiple genes (Daub, Dupanloup et al. 2015). 2DNS measures the evolutionary constraints and specific demographic effects on a gene set by $\mathrm{dN} / \mathrm{dS}$ and $\mathrm{pN} / \mathrm{pS}$ across all the genes in the set and subsequently compares them against a two-dimensional null distribution derived from true gene sets. By inspecting the position of the gene sets, outlier gene sets that are subject to differential evolutionary forces can be identified.

\section{Data collection}

Genes expressed in nervous system of humans and macaques

The genes expressed in the brains of humans and macaques were obtained from the work of Zhu et al. (Zhu, Sousa et al. 2018). In this study, RNA sequencing (RNA-seq) was used to profile the gene expression in brain tissue or single cells from age and brain region-matched specimens of post-mortem humans or rhesus macaques. The samples covered the entire span of both prenatal and postnatal neurodevelopment (prenatal development, early postnatal development, and adulthood) and included 11 areas of the cerebral neocortex (NCX), hippocampus (HIP), amygdala (AMY), striatum (STR), mediodorsal nucleus of thalamus (MD), and cerebellar cortex (CBC). Thus, this study provided a comprehensive comparison of the transcriptomes in the brains of humans and macaques. All of the genes expressed in the human and macaque brains were collected; at the same time, we also collected the genes differentially expressed in one or more brain regions and one or more neurodevelopment stages when samples derived from humans and macaques were compared.

\section{Human Macaque Substitutions and Single-nucleotide polymorphisms in human genes}

The protein coding genes of human and macaque were retrieved from Ensembl (http://www.ensembl.org/) on September 26, 2019. For the two species, only orthologous genes with nonsynonymous ( $\mathrm{dN}$ ) and synonymous (dS) nucleotide substitution were kept. Then, the ratio of $\mathrm{dN}$ to $\mathrm{dS}$, i.e., $\mathrm{dN} / \mathrm{dS}$, were calculated for each pair of orthologs. For genes with multiple transcripts, the longest ones were selected, with a list of 16,492 genes and their $\mathrm{dN} / \mathrm{dS}$ ratios obtained.

The genetic variation data within human were retrieved from the 1000 Genomes Project (https://www.internationalgenome.org/; June 28, 2019)(Sudmant, Rausch et al. 2015). Briefly, a total of 84.4 million variants in 2,504 individuals sampled from 26 populations were downloaded. Then, ANNOVAR, was adopted to detect genetic variants in the genomes (Wang, Li et al. 2010) and the mutation types of exons were distinguished using gene-based annotation. The information comprising 1,001,917 mutation sites on exons was obtained, among which included 594,411 non-synonymous mutation sites and 376,047 synonymous mutation sites. To measure the $\mathrm{pN} / \mathrm{pS}$ ratio (the ratio of non-synonymous to synonymous in different human populations), we divided the $\mathrm{pN}$ value of each gene by the corresponding pS value (David, Enard et al. 2016). A total of 139 genes were discarded due to the missing of pS values, resulting in a list of 18,832 genes for further analyses. 
Then, the two gene lists, i.e., the human and macaque genes with $d N / d S$ and the human genes $\mathrm{pN} / \mathrm{pS}$, were compared, resulting in a set of 16,213 genes with both $\mathrm{dN} / \mathrm{dS}$ and $\mathrm{pN} / \mathrm{pS}$ values. Among these genes, 13,500 were expressed in the brain, with 6,054 genes of heterotopic (differentially expressed in at least one brain area) and 951 genes of heterochronic (differentially expressed in at least one development stage) expression.

\section{Collection of Pathways}

Currently, there are several databases for biological pathways available, such as KEGG (https://www.genome.jp/kegg), BioCyc (https://biocyc.org/) and Reactome (https://reactome.org/). While each source includes some unique pathways, the majority of the items in these databases are overlapped, which means pooling the items from these different sources may provide a more comprehensive coverage of our knowledge on pathways. However, this was conducted in this study for the following reason. In each database, the pathways usually are built and curated by different experts and each database has its own way to define a pathway; and it is common that in different pathway databases, a pathway with same or similar name may consist of quite different number of genes and gene interactions, or multiple pathways in one database may be represented as a single pathway in another database.

To simplify the analysis, we only utilized the collection in KEGG. We retrieved 406 pathways from the KEGG database (June 23, 2019). The pathways were filtered by removing genes not included in the final gene list. Furthermore, pathways with too many or too few genes (i.e., $>1000$ genes or $<10$ genes respectively) were removed, resulting in a list of 313 pathways and a total of 5,053 genes.

\section{Data analysis}

\section{Testing Evolutionary Similarities between Human and Macaque Genes of the Same Pathway}

In this study, it is assumed that genes in the same pathway have evolved in a concert approach, which means genes in a given pathway may share more evolutionary characteristics when compared to those in other pathways. Here, we analyzed the distribution of $\mathrm{dN} / \mathrm{dS}$ (or $\mathrm{pN} / \mathrm{pS}$ ) of the pathway via Analysis of Variance (ANOVA) (Daub, Dupanloup et al. 2015). Briefly, 30 pathways ( 10\% of the 313 pathways analyzed) were randomly selected from the pathway set and the variance component due to differences between pathways ( ) of $\mathrm{dN} / \mathrm{dS}$ (or pN/pS) was computed. Then, genes in these 30 pathways were reshuffled and corresponding to the simulated pathway sets were calculated based on the permuted $\mathrm{dN} / \mathrm{dS}$ (or $\mathrm{pN} / \mathrm{pS}$ ) ratios. The procedure was repeated 5,000 times in order to construct the distribution of $\sigma^{2}{ }_{b}$ of pathway set and the null distribution. If the genes in the same pathway do not share the same evolutionary properties, the distribution of the variance component due to differences between pathways should be similar to the null distribution.

Measuring Nonsynonymous to Synonymous Substitutions at the Pathway Level 
In this study, it was assumed that genes in the same pathway were under the similar evolutionary constraints and evolved cooperatively. Since the divergence of a gene between species and its diversity in human population was measured by $\mathrm{dN} / \mathrm{dS}$ and $\mathrm{pN} / \mathrm{pS}$ respectively, we defined $C d N S$ (cumulative $\mathrm{dN} / \mathrm{dS}$ ) and $C p N S$ to measure the evolutionary characteristics at the pathway level, which was defined as the sum of $\mathrm{dN} / \mathrm{dS}$ (or $\mathrm{pN} / \mathrm{pS}$ ) corresponding to all the genes in a given pathway:

$$
\begin{aligned}
C d N S & =\sum_{g \in \text { pathway }}(d N / d S)_{g} \\
C p N S & =\sum_{g \in \text { pathway }}(p N / p S)_{g}
\end{aligned}
$$

\section{Test selection pressure}

Pathways subject to significant selection pressure were obtained by comparing its $C d N S$ and $C p N S$ value with a null distribution (Daub, Dupanloup et al. 2015). Briefly, the null distribution of CdNS (or CpNS) values were constructed by creating a range of simulated pathways based on the real pathways by considering the fact that the genes in a pathway tended to have similar evolutionary characteristics and genes included in multiple pathways would have smaller $\mathrm{dN} / \mathrm{dS}$ (or $\mathrm{pN} / \mathrm{pS}$ ) ratios. In this procedure, pathways with a Jaccard similarity coefficient (JC) greater than 0.25 were considered to be similar and were merged. Next, we calculated the probability of real pathway and obtained the pathway size. To reduce the influence of pathway size on the result, we calculated the length of the real and random pathway, and put the set of approximate length into a bin to correct for this possible deviation. We repeatedly build a random pathway 100,000 times for each bin (60 bins altogether). We estimated the two-dimensional plane graph of $C d N S$ and $C p N S$ using R packages Kde2d and interp.surface. For each bin, we obtain the density of the grid point according to the pathway of the null distribution.

For our polygenic selection the idea was to construct a two-dimensional plane graph of $C d N S$ vs. $C p N S$ containing both the real and random pathways, in which a pathway under differential evolutionary pressure should be an outlier (Daub, Dupanloup et al. 2015). The probability density of the random pathway was calculated using the R function kde2d and the number of grid point was 400' 400 in each direction. We next interpolated the probability density of the null distribution into the real pathway according to the $C d N S$ and $C p N S$ coordinates. For each real pathway, we compared it with null distribution in the corresponding bin to find the probability density less than or equal to the real pathway, then summed up the corresponding unit of grid point volumes and divided by the total volume to get the $P$ value.

In this way, we have obtained the $P$ value of each real set through multiple testing and we corrected it with a FDR (false discovery rate) $<0.20$. To examine whether most genes contributed to the significance of the pathways, we calculated the contribution of each gene to the CdNS (or CpNS) values in the 
significant pathways. If removing genes with extreme contribution made the pathway insignificant, then the pathway was not considered.

The datasets used in this study, including the $\mathrm{dN} / \mathrm{dS}$ values, $\mathrm{pN} / \mathrm{pS}$ values, the list of KEGG pathways, as well as the genes expressed in the brain of human and macaque, was deposited at: https://doi.org/10.5061/dryad.bk3j9kd94.

\section{Results}

\section{Pathways of Differential evolution in the nervous system}

Of the 16,213 human and macaque genes with $\mathrm{dN} / \mathrm{dS}$ and $\mathrm{pN} / \mathrm{pS}$ ratios, 13,500 were found to be expressed in the brain of human and macaque. Of these brain- expressed genes, 5,053 could be mapped to $313 \mathrm{KEGG}$ pathways. Distribution of the variance of $\mathrm{dN} / \mathrm{dS}$ and $\mathrm{pN} / \mathrm{pS}$ ratios of genes in these pathways showed that genes in the same pathways were more similar to each other than other genes, indicating genes in the same pathway tending to share the same evolutionary properties (Fig. S1).

Then, from these pathways, we identified 31 pathways in the nervous system with significant interspecies (between human and macaque) or intraspecies (in human population) evolutionary differences (FDR < 0.2) (Fig. 1; Table1). Most insignificant pathways had relatively small CdNS and CpNS values, and were located closely along the diagonal (i.e., with roughly equal CdNS and CpNS values). Conversely, the significant pathways scattered in a large range of CdNS and CpNS. Of the significant pathways, some were associated with neurological disease, i.e., Alzheimer's disease (AD), Parkinson's disease (PD) and Huntington's disease (HD). They all had much larger CdNS than CpNS values, probably implicating the interspecies differential evolution of neurodegenerative disease, which was consistent with experimental results of interspecific differences in the pathway of AD, PD and protein localization to endoplasmic (Zhu, Sousa et al. 2018). However, another neurological function related pathway, neuroactive ligand-receptor interaction, had a higher CpNS value, indicating a high diversity of this pathway in human.

We also identified pathways of other categories. Among them, there were pathways involved in the immune system (e.g., cytokine-cytokine receptor interaction, complement and coagulation cascades), immune diseases (e.g., allograft rejection, and graft-versus-host disease) and infectious diseases (e.g., staphylococcus aureus infection, primary immunodeficiency, and measles), all of which had larger CdNS than CpNS values. Also, we found several metabolic-related pathways (e.g., oxidative phosphorylation, pyrimidine metabolism, nicotinate and nicotinamide metabolism, and amino sugar and nucleotide sugar metabolism). Such results indicated that there were functional differences between humans and macaques, or interspecies differences among humans, in the immune and metabolic pathways at the genetic level, which was consistent with earlier gene expression analysis that suggested differences existed in oxidative stress and cytokine levels between species (Eidem, Rinker et al. 2016; Shiina, Blancher et al. 2017; Zhu, Sousa et al. 2018). Our results also suggested that the differences in immune and metabolic functions during the evolution of species were likely to be the result of the interaction of multiple genes. In addition, as an important branch of the organic system, the immune system is 
influenced by environmental, age and other factors (Simon, Hollander et al. 2015), which may be related to the development of different brain regions at different periods. In addition, some metabolic pathways have been found to be associated with brain diseases (Maulik, Sen et al. 2018). Also, some pathways related to organismal system or cellular process were identified (e.g., endocytosis, protein processing in endoplasmic reticulum, olfactory transduction).

\section{Pathways of differential evolution in brain regions and development periods}

It is known that genes are also differentially expressed in different brain regions and developmental periods (Zhu, Sousa et al. 2018). To explore the evolution properties of pathways related to brain regions and neurodevelopment, we analyzed the genes differentially expressed in brain regions, or neurodevelopment stages between humans and macaques. Of these genes, 2,145 heterotopically expressed genes and 231 heterochronically expressed genes were mapped to KEGG pathways. Further, we identified 8 and 4 pathways that were evolutionarily different, respectively (Table $2 \& 3$ ). All of these pathways were also included in the list of 31 pathways identified from the genes of the whole brain data.

We found that cytokine-cytokine receptor interactions as well as complement and coagulation cascades were the common pathways of heterotopic and heterochronic results, indicating significant differences in specific immune functions of different brain regions and developmental stages among species. The immune response in $A D$ brain showed differences in brain region dependence, and the immune process has potential changes with longer brain development time (Galatro, Holtman et al. 2017; Prokop, Miller et al. 2019). In addition, we found that other immune signals and immune system pathways occurred in the heterotopic results, suggesting that they showed significant differences in different brain regions of the species. The importance of immune cells in neurodevelopment is now recognized, and in fact cytokines are ubiquitous in the developing brain, directing neuronal differentiation and axonal guidance (Deverman and Patterson 2009). Therefore, the immune system is closely related to the nervous system.

In addition, we observed evolutionary differences in the neuroactive ligand-receptor interaction and Parkinson's disease pathway in different brain regions of specific species. The death of certain neuronal population leads to the occurrence of PD, indicating that specific brain regions are more involved in the formation of PD pathological features. Consistent with the neuroimaging studies of PD as described in Wen et al. (Wen, Chan et al. 2016). Recent studies have shown that proteins involved in the process of PD also affect the pathway of neuroactive ligand-receptor interaction (Kong, Liang et al. 2015). We found that structural differences in brain regions affect the production of PD and that some of the pathways are correlated. We also observed pathways of energy metabolism and organismal system, suggesting differences in metabolism and environmental adaption between brain regions of species. Oxidative phosphorylation, in particular, is associated with neurodegenerative disease, Snyder et al. have shown that it is involved in the early activity of brain regions associated with AD formation (Snyder, Shell et al. 2017). In the heterochronic results, protein processing and atherosclerosis varies at multiple periods of brain development. Recently, changes in the stable properties of protein have been identified as one of the main markers of aging, and the accumulation of protein folding errors in the endoplasmic reticulum 
further increases the risk of neurological disease (Lopez-Otin, Blasco et al. 2013; Martinez, Duran-Aniotz et al. 2017). Therefore, aging could induce protein denaturation, which could affect the normal physiological function of the nervous system. Note that the risk of atherosclerosis increases with age consistent with our findings (Childs, Gluscevic et al. 2017).

These 10 pathways have evolutionary differences in specific brain regions or at different stages of development. The differences in brain function caused by evolution are reflected in the expression level. The analysis of the common and unique pathways of heterotopic and heterochronic results will contribute to understanding of the evolutionary mechanisms of the human nervous system.

\section{The interaction network of different evolutionary pathways}

To explore the interaction relationship between interspecies differential evolutionary pathways in the nervous system and understand the evolutionary mechanism of human brain systematically, we conducted pathway crosstalk analysis on 31 different pathways (Hu, Xin et al. 2017). Except the ribosome pathway (which was isolated and did not share genes with other pathways in the list), the other 30 pathways interacted with each other and a pathway crosstalk network was constructed (Fig. 2).

In the network of pathways, there were 30 nodes and 167 edges, among which 16 pathways had more than 10 edges and 1 pathway had more than 20 edges, implicating a close correction between pathways. Based on the crosstalk between them, these pathways could be divided into four parts. On the left are the most numerous immune pathways while the bottom presents the metabolic pathway. In the middle are signaling pathways (e.g., protein processing in endoplasmic reticulum, chemokine signaling pathway etc.) that were broadly related to the rest of the pathways. On the right are the neural pathways, which are closely related to oxidative phosphorylation, of which had a significant correlation between them. Recent studies have confirmed correlations between several pathways and the nervous system (Brandolini, d'Angelo et al. 2019; Pollen, Bhaduri et al. 2019; Singh, Kukreti et al. 2019). For example, the process of oxidative was involved in the regulation of neurological disorders (Singh, Kukreti et al. 2019).The pathway network suggests that there is indeed a correlation between pathways with different functions in the evolutionary process. Together, these findings show that the evolution of the human nervous system is not caused by the independent action of pathways, and this difference is likely to result from the interaction of pathways.

\section{Discussion}

In this study, we used pathways as research units to measure the level of evolution by comparing the twodimensional substitute ratio with random pathways, demonstrated the pathways of evolutionary difference between human and macaque nervous systems, and further explored the reasons for the formation of the difference. We found that in addition to neurological disease these results contain multiple signaling pathways, as well as some typical immune and metabolic pathways. We also found some of these pathways are the heterotopic and heterochronic in nature. The crosstalk analysis showed 
that the pathways had specific correlation. The method is more comprehensive from the perspective of evolution to find significant pathways between species, not limited to a single gene or pathway.

It has long been recognized that the development of the human brain is slower than that of macaques and that brain regions have more space for connectivity, which opens up the possibility of differential evolution of immune response, metabolism and, in particular, functionality (Preuss, Caceres et al. 2004; Rilling, Glasser et al. 2008; Silbereis, Pochareddy et al. 2016; Palomero-Gallagher and Zilles 2019). Consistent with the differences in the components of human and macaque neuritic plaque found in previous experiments (Zhou, Jiang et al. 2018), many regions of the human brain different from the corresponding regions in macaques, which lead to the development of neural circuits, then affect the functional changes of brain regions (Petrides, Cadoret et al. 2005; Buckner and DiNicola 2019; PalomeroGallagher and Zilles 2019). In addition to differences in brain structure, new findings suggest that a healthy lifestyle with age can protect neurons from degeneration (Raefsky and Mattson 2017). Understanding the evolutionary possibilities of heterotopia and heterochronia could provide insight into their disturbance in the pathways and the mechanism of brain evolution, as well as provide insights for the different pathway research of human beings and other primates. However, we also identified more intuitive pathways that are influenced by environmental factors, such as circadian entrainment. It is unclear how evolutionary constraints may act on the pathway, but epigenetic process has been found to be able to recode the genome in response to environmental stresses on brain (Bale 2015).

Of significance, we identified the correlation between pathways through crosstalk analysis. In fact, $A D$ shares some symptoms with $H D$ and patients with $A D$ have a higher risk of $P D$, which could explain the higher overlap significance of the neurological diseases (Hensman Moss, Flower et al. 2017; Stephenson, Nutma et al. 2018). Neurological disease affected by oxidative stress, mitochondrial dysfunction, immune inflammation, and so on are confirmed studies (Tansey and Goldberg 2010; Singh, Kukreti et al. 2019; Winiarska-Mieczan, Baranowska-Wojcik et al. 2020). For example, PD is strongly associated with abnormal lipid metabolism (Xicoy, Wieringa et al. 2019), and abnormal tau protein in AD is involved in inflammatory response (Akiyama, Barger et al. 2000). In a recent research, Li et al. demonstrated through molecular mechanisms that the correlation of the NOD-like receptor signaling pathway for glial regulation (Li, Li et al. 2019). Microglia plays an important role in brain inflammation and neural circuits, and influences the occurrence of some neurological diseases by regulating immune function (Adams, Johansen et al. 2011; Schafer and Stevens 2015). This could explain the association of signaling pathways with neural pathways. In addition to associations with neurological diseases, we also found complex associations within and between immune and metabolic pathways, which was consistent with previous findings that metabolism plays a key role in regulating immunity. In addition, inflammation has been shown to have a significant impact on metabolism (Pearce, Poffenberger et al. 2013; O'Neill and Pearce 2016; Buck, Sowell et al. 2017). These results suggested that immune, metabolic and signal transduction pathways jointly participate in the process of human brain evolution, providing insight into the association between differential evolutionary pathways and a more comprehensive reference for the evolution of nervous system. 
In addition to the evolutionarily different pathways that we have identified, a large amount of exploration of the evolution of the human brain has uncovered other distinct evolutionary pathways. Kurochkin et al. found correlations between autism spectrum disorder (ASD) and metabolic pathways (e.g., glycerophospholipid metabolism, nicotinate and nicotinamide metabolism) through interspecies with ASD gene expression analysis (Kurochkin, Khrameeva et al. 2019). In fact, studies have shown a positive correlation between the severity of ASD and immune dysfunction (Adams, Johansen et al. 2011). Schizophrenia is also a pathway that evolutionarily diverges between humans and macaques (Zhu, Sousa et al. 2018; Wei, de Lange et al. 2019). The bidirectional connection between the nervous system and the immune system is facilitated by the defined lymphoid system and specific metabolites in the brain regulate immune cells that could stimulate lymphoid (Louveau, Smirnov et al. 2015). Combined with the above analysis and KEGG Pathway Maps, the differential evolutionary pathways could be summarized into a chart (Fig. 3). The images show the underlying immune, metabolic and signaling pathways at the center. Changes in these pathways affect each other and could further affect peripheral disease pathways.

Neurological diseases and related signaling pathway contain metabolic gene families: COX, NDU and UQCR. Despite this, the pathway contains genes with specific functions, for example the cytotoxicity of freak HTT protein can induce HD (Song, Li et al. 2018). In addition to the metabolic gene family, immune pathways include the IL, CXC and CC gene families, although the specific FAS gene family is also included in immune diseases. Studies on the response of CCL gene family to virus infection in species and interspecific differences of FAS gene family have recently been demonstrated (Buse and Markert 2019; Zhou, Qiao et al. 2019). Interestingly, some genes of the CAMK2 and PRKA gene families are shared by olfactory transduction and circadian entrainment pathways, moreover these genes are related to the change of gravity, saline adaptability and other environmental factors (Chen, Lu et al. 2017; Abe, Yamaoka et al. 2019). The analysis of the relationship between gene families in the pathways indicates that there are extensive gene family connections between evolutionarily different pathways and the relationship could causal. For example, COX gene family mutations lead to genetic changes in neurological disease that could induce disease. These investigations possibly reveal the characteristics of evolutionary pathways and contribute to a deeper and accurate understanding of the evolutionary mechanisms of the human brain.

In this study, we identified the pathways of differential evolution in human brain, analyzed four major functions that distinguish human from macaques, including nerve, signal transduction, immune and metabolic pathways, as well as presented evidence at the expression level. We demonstrated that 10 pathways are associated with differences in brain structure and development periods and found correlations between the pathways. Our results provide a reference for the development of the human brain. Due to the limitations of human studies, our results seem to provide support for the establishment of animal brain models. Future work on evolutionary mechanisms at the gene level in the nervous system, extrapolating on differences in evolutionary pathways between humans and macaques, and the exploration of gene families will likely shed light on neurological mechanisms. 


\section{Declarations}

Acknowledgements The authors thank Mr. Yonglin Peng and Ms. Meng Yuan for helpful discussions in preparation of the manuscript.

Availability of Data and Material All data generated or analyzed during this study are included in this published article and its supplementary information files.

Funding Information This work was supported by grants from National Key Research and Development Program of China (No.2016YFC0906300), National Natural Science Foundation of China (No.91746205 \& 31271411).

\section{Authors' contributions}

YM, FC and JW designed the experiments. YM, CC, MZ and JW performed experiments and data analysis. YM, FC and JW wrote the manuscript. All authors read and approved the final manuscript.

\section{Compliance with ethical standards}

Conflict of Interests The authors declare that they have no conflict of interest.

Ethics Approval Not applicable.

Consent to Participate Not applicable.

Consent for Publication Not applicable.

\section{References}

Abe, C., Y. Yamaoka, et al. (2019). "Hypergravity-induced plastic alteration of the vestibulo-sympathetic reflex involves decrease in responsiveness of CAMK2-expressing neurons in the vestibular nuclear complex." J Physiol Sci69(6): 903-917.

Adams, J. B., L. J. Johansen, et al. (2011). "Gastrointestinal flora and gastrointestinal status in children with autism-comparisons to typical children and correlation with autism severity." BMC Gastroenterol11: 22.

Akiyama, H., S. Barger, et al. (2000). "Inflammation and Alzheimer's disease." Neurobiol Aging21(3): 383421.

Ardesch, D. J., L. H. Scholtens, et al. (2019). "The human connectome from an evolutionary perspective." Progress in Brain Research250: 129-151.

Bale, T. L. (2015). "Epigenetic and transgenerational reprogramming of brain development." Nat Rev Neurosci16(6): 332-344. 
Berg, J. J. and G. Coop (2014). "A population genetic signal of polygenic adaptation." PLoS Genet10(8): e1004412.

Bergey, C. M., M. Lopez, et al. (2018). "Polygenic adaptation and convergent evolution on growth and cardiac genetic pathways in African and Asian rainforest hunter-gatherers." Proc Natl Acad Sci U S A115(48): E11256-E11263.

Brandolini, L., M. d'Angelo, et al. (2019). "Chemokine Signaling in Chemotherapy-Induced Neuropathic Pain." Int J Mol Sci20(12).

Buck, M. D., R. T. Sowell, et al. (2017). "Metabolic Instruction of Immunity." Cell169(4): 570-586.

Buckner, R. L. and L. M. DiNicola (2019). "The brain's default network: updated anatomy, physiology and evolving insights." Nat Rev Neurosci20(10): 593-608.

Buse, E. and U. R. Markert (2019). "The immunology of the macaque placenta: A detailed analysis and critical comparison with the human placenta." Crit Rev Clin Lab Sci56(2): 118-145.

Chen, Y. H., C. W. Lu, et al. (2017). "Revealing the Saline Adaptation Strategies of the Halophilic Bacterium Halomonas beimenensis through High-throughput Omics and Transposon Mutagenesis Approaches." Sci Rep7(1): 13037.

Chikina, M., J. D. Robinson, et al. (2016). "Hundreds of Genes Experienced Convergent Shifts in Selective Pressure in Marine Mammals." Mol Biol Evol33(9): 2182-2192.

Childs, B. G., M. Gluscevic, et al. (2017). "Senescent cells: an emerging target for diseases of ageing." Nat Rev Drug Discov16(10): 718-735.

Daub, J. T., I. Dupanloup, et al. (2015). "Inference of Evolutionary Forces Acting on Human Biological Pathways." Genome Biol Evol7(6): 1546-1558.

David, M. M., D. Enard, et al. (2016). "Comorbid Analysis of Genes Associated with Autism Spectrum Disorders Reveals Differential Evolutionary Constraints." PLoS One11(7): e0157937.

de Juan, D., F. Pazos, et al. (2013). "Emerging methods in protein co-evolution." Nat Rev Genet14(4): 249261.

Deverman, B. E. and P. H. Patterson (2009). "Cytokines and CNS development." Neuron64(1): 61-78.

Eidem, H. R., D. C. Rinker, et al. (2016). "Comparing human and macaque placental transcriptomes to disentangle preterm birth pathology from gestational age effects." Placenta41: 74-82.

Galatro, T. F., I. R. Holtman, et al. (2017). "Transcriptomic analysis of purified human cortical microglia reveals age-associated changes." Nat Neurosci20(8): 1162-1171. 
Hensman Moss, D. J., M. D. Flower, et al. (2017). "Huntington's disease blood and brain show a common gene expression pattern and share an immune signature with Alzheimer's disease." Sci Rep7: 44849.

Hu, Y. S., J. Xin, et al. (2017). "Analyzing the genes related to Alzheimer's disease via a network and pathway-based approach." Alzheimers Res Ther9(1): 29.

Kong, Y., X. Liang, et al. (2015). "High Throughput Sequencing Identifies MicroRNAs Mediating alphaSynuclein Toxicity by Targeting Neuroactive-Ligand Receptor Interaction Pathway in Early Stage of Drosophila Parkinson's Disease Model." PLoS One10(9): e0137432.

Kurochkin, I., E. Khrameeva, et al. (2019). "Metabolome signature of autism in the human prefrontal cortex." Commun Biol2: 234.

Li, Y., Q. Li, et al. (2019). "Long Noncoding RNA Expression Profile in BV2 Microglial Cells Exposed to Lipopolysaccharide." Biomed Res Int2019: 5387407.

Lopez-Otin, C., M. A. Blasco, et al. (2013). "The hallmarks of aging." Cell153(6): 1194-1217.

Louveau, A., I. Smirnov, et al. (2015). "Structural and functional features of central nervous system lymphatic vessels." Nature523(7560): 337-341.

Martinez, G., C. Duran-Aniotz, et al. (2017). "Endoplasmic reticulum proteostasis impairment in aging." Aging Cell16(4): 615-623.

Maulik, U., S. Sen, et al. (2018). "Detecting TF-miRNA-gene network based modules for 5hmC and 5mC brain samples: a intra- and inter-species case-study between human and rhesus." BMC Genet19(1): 9.

Muchnik, S. K., B. Lorente-Galdos, et al. (2019). "Modeling the Evolution of Human Brain Development Using Organoids." Cell179(6): 1250-1253.

O'Neill, L. A. and E. J. Pearce (2016). "Immunometabolism governs dendritic cell and macrophage function." J Exp Med213(1): 15-23.

Palomero-Gallagher, N. and K. Zilles (2019). "Differences in cytoarchitecture of Broca's region between human, ape and macaque brains." Cortex118: 132-153.

Pattabiraman, K., S. K. Muchnik, et al. (2020). "The evolution of the human brain and disease susceptibility." Curr Opin Genet Dev65: 91-97.

Pearce, E. L., M. C. Poffenberger, et al. (2013). "Fueling immunity: insights into metabolism and lymphocyte function." Science342(6155): 1242454.

Petrides, M., G. Cadoret, et al. (2005). "Orofacial somatomotor responses in the macaque monkey homologue of Broca's area." Nature435(7046): 1235-1238. 
Pollen, A. A., A. Bhaduri, et al. (2019). "Establishing Cerebral Organoids as Models of Human-Specific Brain Evolution." Cell176(4): 743-756 e717.

Preuss, T. M., M. Caceres, et al. (2004). "Human brain evolution: insights from microarrays." Nat Rev Genet5(11): 850-860.

Prokop, S., K. R. Miller, et al. (2019). "Impact of TREM2 risk variants on brain region-specific immune activation and plaque microenvironment in Alzheimer's disease patient brain samples." Acta Neuropathol138(4): 613-630.

Raefsky, S. M. and M. P. Mattson (2017). "Adaptive responses of neuronal mitochondria to bioenergetic challenges: Roles in neuroplasticity and disease resistance." Free Radic Biol Med102: 203-216.

Rilling, J. K. (2014). "Comparative primate neuroimaging: insights into human brain evolution." Trends Cogn Sci18(1): 46-55.

Rilling, J. K., M. F. Glasser, et al. (2008). "The evolution of the arcuate fasciculus revealed with comparative DTI." Nat Neurosci11(4): 426-428.

Sakai, T., S. Hirata, et al. (2012). "Fetal brain development in chimpanzees versus humans." Curr Biol22(18): R791-792.

Schafer, D. P. and B. Stevens (2015). "Microglia Function in Central Nervous System Development and Plasticity." Cold Spring Harb Perspect Biol7(10): a020545.

Shiina, T., A. Blancher, et al. (2017). "Comparative genomics of the human, macaque and mouse major histocompatibility complex." Immunology 150(2): 127-138.

Silbereis, J. C., S. Pochareddy, et al. (2016). "The Cellular and Molecular Landscapes of the Developing Human Central Nervous System." Neuron89(2): 248-268.

Simon, A. K., G. A. Hollander, et al. (2015). "Evolution of the immune system in humans from infancy to old age." Proc Biol Sci282(1821): 20143085.

Singh, A., R. Kukreti, et al. (2019). "Oxidative Stress: A Key Modulator in Neurodegenerative Diseases." Molecules24(8).

Snyder, B., B. Shell, et al. (2017). "Chronic intermittent hypoxia induces oxidative stress and inflammation in brain regions associated with early-stage neurodegeneration." Physiol Rep5(9).

Song, H., H. Li, et al. (2018). "Targeting Gpr52 lowers mutant HTT levels and rescues Huntington's disease-associated phenotypes." Brain141(6): 1782-1798.

Sousa, A. M. M., K. A. Meyer, et al. (2017). "Evolution of the Human Nervous System Function, Structure, and Development." Cell170(2): 226-247. 
Sousa, A. M. M., Y. Zhu, et al. (2017). "Molecular and cellular reorganization of neural circuits in the human lineage." Science358(6366): 1027-1032.

Srivastava, M., O. Simakov, et al. (2010). "The Amphimedon queenslandica genome and the evolution of animal complexity." Nature466(7307): 720-726.

Stephenson, J., E. Nutma, et al. (2018). "Inflammation in CNS neurodegenerative diseases." Immunology 154(2): 204-219.

Stranger, B. E., E. A. Stahl, et al. (2011). "Progress and promise of genome-wide association studies for human complex trait genetics." Genetics187(2): 367-383.

Sudmant, P. H., T. Rausch, et al. (2015). "An integrated map of structural variation in 2,504 human genomes." Nature526(7571): 75-81.

Tansey, M. G. and M. S. Goldberg (2010). "Neuroinflammation in Parkinson's disease: its role in neuronal death and implications for therapeutic intervention." Neurobiol Dis37(3): 510-518.

Verendeev, A. and C. C. Sherwood (2017). "Human Brain Evolution." Curr Opin Behav Sci16: 41-45.

Wang, K., M. Li, et al. (2010). "ANNOVAR: functional annotation of genetic variants from high-throughput sequencing data." Nucleic Acids Res38(16): e164.

Wei, Y., S. C. de Lange, et al. (2019). "Genetic mapping and evolutionary analysis of human-expanded cognitive networks." Nat Commun10(1): 4839.

Wen, M. C., L. L. Chan, et al. (2016). "Depression, anxiety, and apathy in Parkinson's disease: insights from neuroimaging studies." Eur J Neurol23(6): 1001-1019.

Winiarska-Mieczan, A., E. Baranowska-Wojcik, et al. (2020). "The Role of Dietary Antioxidants in the Pathogenesis of Neurodegenerative Diseases and Their Impact on Cerebral Oxidoreductive Balance." Nutrients12(2).

Xicoy, H., B. Wieringa, et al. (2019). "The Role of Lipids in Parkinson's Disease." Cells8(1).

Yin, S., K. Lu, et al. (2020). "Transcriptomic and open chromatin atlas of high-resolution anatomical regions in the rhesus macaque brain." Nat Commun11(1): 474.

Zhou, F. Q., J. Jiang, et al. (2018). "Lack of human-like extracellular sortilin neuropathology in transgenic Alzheimer's disease model mice and macaques." Alzheimers Res Ther10(1): 40.

Zhou, Y., H. Qiao, et al. (2019). "Immune and cytokine/chemokine responses of PBMCs in rotavirusinfected rhesus infants and their significance in viral pathogenesis." J Med Virol91(8): 1448-1469. 
Zhu, Y., A. M. M. Sousa, et al. (2018). "Spatiotemporal transcriptomic divergence across human and macaque brain development." Science362(6420).

\section{Tables}

Table 1. Differentially evolutionary pathways in genes expressed in the brain of human and macaque 


\begin{tabular}{|c|c|c|c|c|c|c|c|}
\hline Pathway & $\begin{array}{l}\text { Gene } \\
\text { number }\end{array}$ & $\begin{array}{l}\text { Set } \\
\text { length } \\
\text { (kb) }\end{array}$ & CdNS & CpNS & $\begin{array}{l}\mathrm{p}- \\
\text { value }\end{array}$ & $\begin{array}{l}\text { FDR } \\
\mathrm{a}\end{array}$ & Gene included $^{\mathrm{b}}$ \\
\hline $\begin{array}{l}\text { Neuroactive ligand- } \\
\text { receptor interaction }\end{array}$ & 215 & 902 & 38.27 & 44.80 & $\begin{array}{l}7.95 \\
110^{-34}\end{array}$ & $\begin{array}{l}2.49 \\
10^{-31}\end{array}$ & 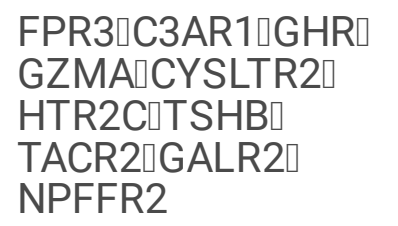 \\
\hline $\begin{array}{l}\text { Cytokine-cytokine } \\
\text { receptor interaction }\end{array}$ & 175 & 618 & 62.62 & 44.56 & $\begin{array}{l}3.10 \\
10^{-24}\end{array}$ & $\begin{array}{l}4.85 \\
10^{-22}\end{array}$ & 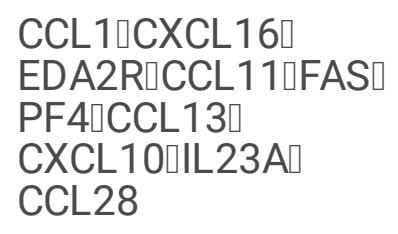 \\
\hline Ribosome & 79 & 190 & 21.73 & 18.52 & $\begin{array}{l}3.83 \\
10^{-18}\end{array}$ & $\begin{array}{l}4.00 \\
10^{-16}\end{array}$ & 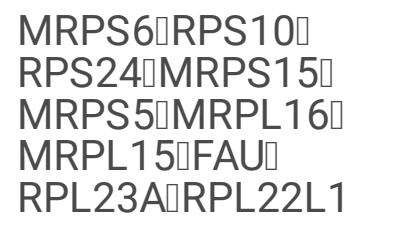 \\
\hline Parkinson's disease & 84 & 282 & 32.78 & 21.93 & $\begin{array}{l}1.01 \\
1 \\
' 10^{-14}\end{array}$ & $\begin{array}{l}7.88 \\
10^{-13}\end{array}$ & 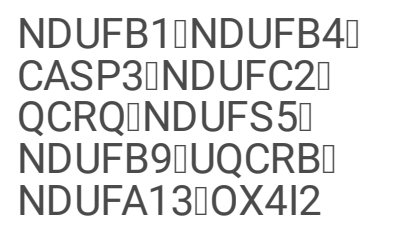 \\
\hline $\begin{array}{l}\text { Oxidative } \\
\text { phosphorylation }\end{array}$ & 77 & 216 & 30.09 & 21.03 & $\begin{array}{l}9.97 \\
1 \\
10^{-14}\end{array}$ & $\begin{array}{l}6.24 \\
10^{-12}\end{array}$ & 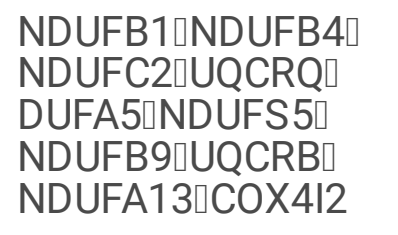 \\
\hline Lysosome & 113 & 447 & 27.88 & 27.85 & $\begin{array}{l}1.43 \\
110^{-12}\end{array}$ & $\begin{array}{l}7.44 \\
10^{-11}\end{array}$ & 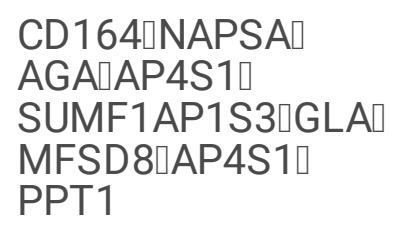 \\
\hline $\begin{array}{l}\text { Complement and } \\
\text { coagulation } \\
\text { cascades }\end{array}$ & 54 & 197 & 22.78 & 14.32 & $\begin{array}{l}1.64 \\
10^{-10}\end{array}$ & $\begin{array}{l}7.35 \\
' 10^{-9}\end{array}$ & 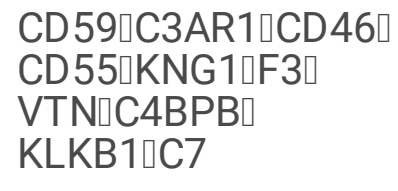 \\
\hline $\begin{array}{l}\text { Non-alcoholic fatty } \\
\text { liver disease } \\
\text { (NAFLD) }\end{array}$ & 111 & 427 & 37.33 & 25.77 & $\begin{array}{l}1.99 \\
' 10^{-8}\end{array}$ & $\begin{array}{l}7.77 \\
' 10^{-7}\end{array}$ & 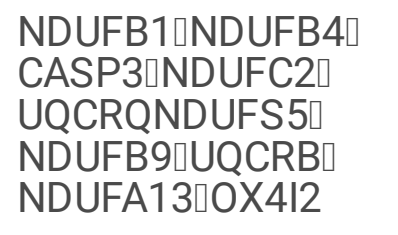 \\
\hline $\begin{array}{l}\text { Hematopoietic cell } \\
\text { lineage }\end{array}$ & 56 & 221 & 25.49 & 15.47 & $\begin{array}{l}1.04 \\
' 10^{-6}\end{array}$ & $\begin{array}{l}3.60 \\
' 10^{-5}\end{array}$ & 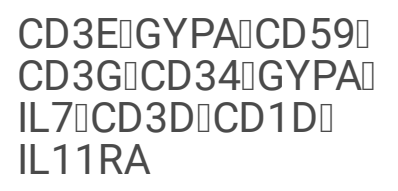 \\
\hline $\begin{array}{l}\text { Protein processing } \\
\text { in endoplasmic }\end{array}$ & 131 & 555 & 22.11 & 26.61 & $\begin{array}{l}4.94 \\
' 10^{-5}\end{array}$ & $\begin{array}{l}1.55 \\
' 10^{-3}\end{array}$ & $\begin{array}{l}\text { SAR1AIDNAJC5G! } \\
\text { XBP10YOD10 }\end{array}$ \\
\hline
\end{tabular}


reticulum

SEL1L2"DNAJC5Gם CRYABIDNAJC5B!

XBP1SEC31B

\begin{tabular}{|c|c|c|c|c|c|c|c|}
\hline Alzheimer's disease & 114 & 521 & 39.95 & 27.31 & $\begin{array}{l}2.54 \\
' 10^{-4}\end{array}$ & $\begin{array}{l}7.23 \\
' 10^{-3}\end{array}$ & 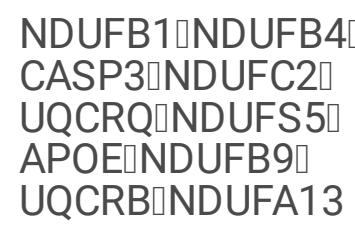 \\
\hline
\end{tabular}

Tight junction

143

$657 \quad 24.08 \quad 28.40$

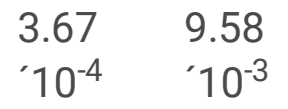

CD1E【ACTR3!

TUBA1C $\square$ JAM2 $\square$

PRKACG $\triangle A C T R 3 C \square$

WASIMARVELD3!

CLDN19LCD1D

$\begin{array}{lllllll}\text { Peroxisome } & 72 & 250 & 18.64 & 19.29 & 5.44 & 1.31 \\ & & & & & 110^{-4} & { }^{\prime} 10^{-2}\end{array}$

PECRIGSTK1!

MPV17ロMPV17L2ם

ACSL6ロPMVK

AMACR $\square$ CROT!

HSD17B4[PRDX1

Fanconi anemia

$42 \quad 193$

$17.27 \quad 11.26$

1.16

$' 10^{-3} \quad 10^{-2}$

UBE2TIRPA3ロ

EME1TPOLH!

FANCADMLH1

FANCM $\square$ RMI1

FANCC $\square$ FANCI

Olfactory

transduction

57

222

13.29

16.66

$\begin{array}{ll}1.50 & 3.13 \\ ' 10^{-3} & ' 10^{-2}\end{array}$

PRKACG $10 R 2 D 3 \square$

OR8G5[OR10Q10

OR52B6ロOR52A1!

OR8D1DOR4D2"

GNG7ロOR2AT4

\begin{tabular}{|c|c|c|c|c|c|c|c|}
\hline RNA transport & 121 & 492 & 24.37 & 24.39 & $\begin{array}{l}2.30 \\
10^{-3}\end{array}$ & $\begin{array}{l}4.23 \\
' 10^{-2}\end{array}$ & 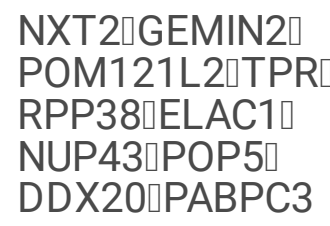 \\
\hline
\end{tabular}

Pyrimidine

metabolism

88

$88 \quad 309$

$309 \quad 16.52$

20.47

2.61

$' 10^{-3}$
4.54

$' 10^{-2}$
PRIM2[NME6]

POLR3G DCK

RRM20DCTPP1ם

PRIM10DPYD

NT5M!POLR3C

Intestinal immune 23

network for IgA

production $\begin{array}{lll}64 & 9.68 & 5.64\end{array}$

9.68

$\begin{array}{lll}5.64 & 3.91 & 6.29 \\ & ' 10^{-3} & ' 10^{-2}\end{array}$

ICOSIIL15RA]

TNFSF13BD

CXCL12 12TNFSF13!

CCL28CCL25!

TNFRSF174CCR9!

IL6

\begin{tabular}{|c|c|c|c|c|c|c|c|}
\hline Huntington's disease & 135 & 636 & 42.33 & 31.28 & $\begin{array}{l}4.02 \\
' 10^{-3}\end{array}$ & $\begin{array}{l}6.29 \\
' 10^{-2}\end{array}$ & 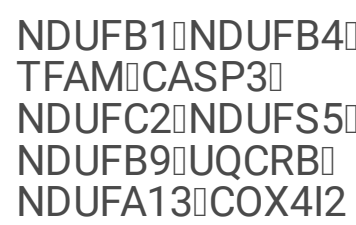 \\
\hline
\end{tabular}




\begin{tabular}{|c|c|c|c|c|c|c|c|}
\hline $\begin{array}{l}\text { Staphylococcus } \\
\text { aureus infection }\end{array}$ & 22 & 84 & 10.56 & 5.34 & $\begin{array}{l}4.22 \\
' 10^{-3}\end{array}$ & $\begin{array}{l}6.30 \\
10^{-2}\end{array}$ & 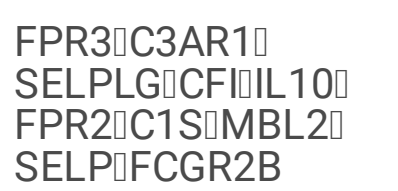 \\
\hline HTLV-I infection & 204 & 930 & 34.17 & 36.11 & $\begin{array}{l}6.15 \\
' 10^{-3}\end{array}$ & $\begin{array}{l}8.71 \\
' 10^{-2}\end{array}$ & 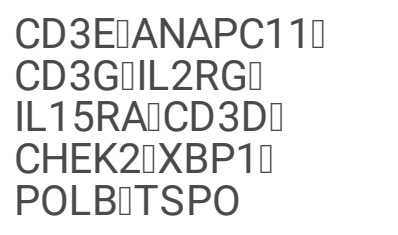 \\
\hline $\begin{array}{l}\text { Circadian } \\
\text { entrainment }\end{array}$ & 81 & 602 & 9.12 & 11.63 & $\begin{array}{l}6.40 \\
' 10^{-3}\end{array}$ & $\begin{array}{l}8.71 \\
' 10^{-2}\end{array}$ & 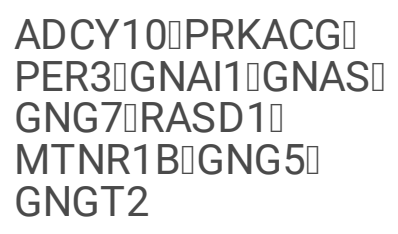 \\
\hline Allograft rejection & 11 & 26 & 5.78 & 2.20 & $\begin{array}{l}9.55 \\
1 \\
\prime-3\end{array}$ & $\begin{array}{l}1.20 \\
' 10^{-1}\end{array}$ & 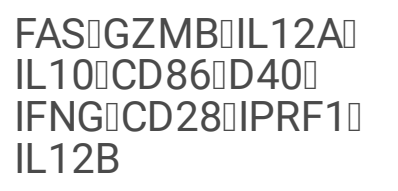 \\
\hline $\begin{array}{l}\text { Chemokine } \\
\text { signaling pathway }\end{array}$ & 135 & 614 & 27.49 & 27.18 & $\begin{array}{l}1.36 \\
1 \\
\prime\end{array}$ & $\begin{array}{l}1.64 \\
' 10^{-1}\end{array}$ & 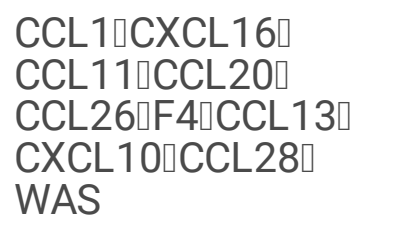 \\
\hline Measles & 96 & 425 & 28.14 & 18.88 & $\begin{array}{l}1.56 \\
1 \\
\prime-2\end{array}$ & $\begin{array}{l}1.77 \\
' 10^{-1}\end{array}$ & 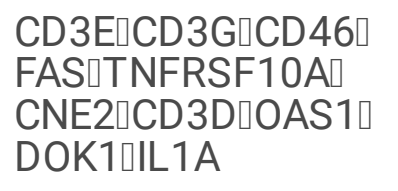 \\
\hline $\begin{array}{l}\text { Fluid shear stress } \\
\text { and atherosclerosis }\end{array}$ & 108 & 450 & 20.36 & 21.41 & $\begin{array}{l}1.61 \\
' 10^{-2}\end{array}$ & $\begin{array}{l}1.77 \\
' 10^{-1}\end{array}$ & 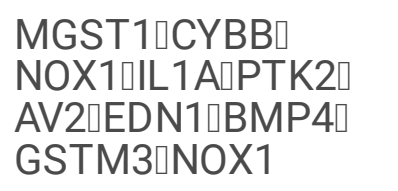 \\
\hline $\begin{array}{l}\text { NOD-like receptor } \\
\text { signaling pathway }\end{array}$ & 123 & 543 & 34.72 & 27.49 & $\begin{array}{l}1.64 \\
' 10^{-2}\end{array}$ & $\begin{array}{l}1.77 \\
' 10^{-1}\end{array}$ & 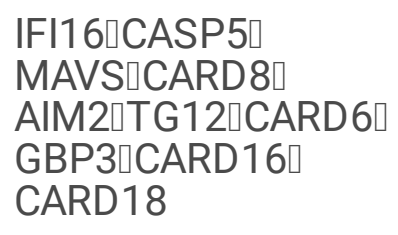 \\
\hline $\begin{array}{l}\text { Nicotinate and } \\
\text { nicotinamide } \\
\text { metabolism }\end{array}$ & 26 & 91 & 5.73 & 7.24 & $\begin{array}{l}1.90 \\
1 \\
' 10^{-2}\end{array}$ & $\begin{array}{l}1.91 \\
' 10^{-1}\end{array}$ & 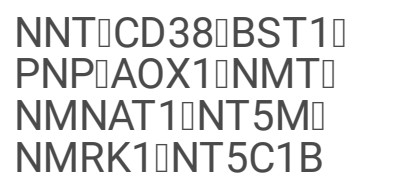 \\
\hline $\begin{array}{l}\text { Amino sugar and } \\
\text { nucleotide sugar } \\
\text { metabolism }\end{array}$ & 42 & 172 & 5.32 & 8.87 & $\begin{array}{l}1.96 \\
1 \\
' 10^{-2}\end{array}$ & $\begin{array}{l}1.91 \\
' 10^{-1}\end{array}$ & 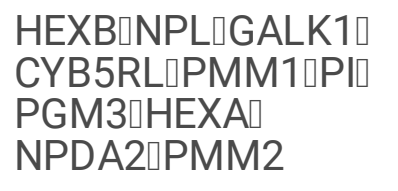 \\
\hline $\begin{array}{l}\text { Graft-versus-host } \\
\text { disease }\end{array}$ & 12 & 40 & 5.92 & 3.07 & $\begin{array}{l}1.96 \\
10^{-2}\end{array}$ & $\begin{array}{l}1.91 \\
' 10^{-1}\end{array}$ & 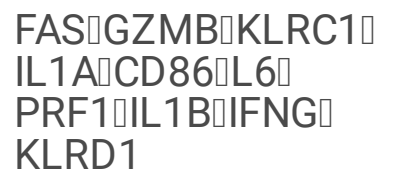 \\
\hline
\end{tabular}




\begin{tabular}{|c|c|c|c|c|c|c|c|}
\hline Endocytosis & 212 & 1058 & 33.45 & 40.22 & $\begin{array}{l}2.02 \\
10^{-2}\end{array}$ & $\begin{array}{l}1.91 \\
' 10^{-1}\end{array}$ & 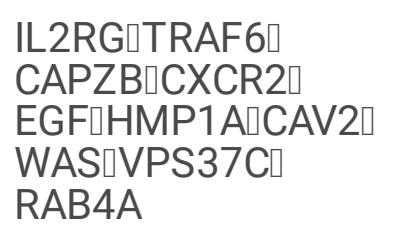 \\
\hline $\begin{array}{l}\text { Primary } \\
\text { immunodeficiency }\end{array}$ & 22 & 85 & 10.07 & 4.56 & $\begin{array}{l}1.68 \\
' 10^{-3}\end{array}$ & $\begin{array}{l}3.29 \\
' 10^{-2}\end{array}$ & 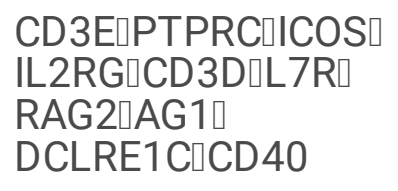 \\
\hline Base excision repair & 31 & 94 & 9.74 & 9.55 & $\begin{array}{l}7.03 \\
' 10^{-3}\end{array}$ & $\begin{array}{l}9.17 \\
' 10^{-2}\end{array}$ & 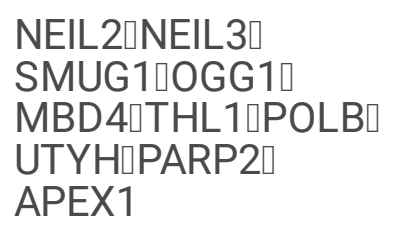 \\
\hline
\end{tabular}

Note. ${ }^{a}$ Pathways with FDR $<0.2$ are listed.

${ }^{b}$ In each pathway, the top 10 genes with the highest $d N / d S$ or $p N / p S$ are listed.

Table 2. Differentially evolutionary pathways in genes heterotopically expressed in the brain of human and macaque 


\begin{tabular}{|c|c|c|c|c|c|c|c|}
\hline Pathway & $\begin{array}{l}\text { Gene } \\
\text { number }\end{array}$ & $\begin{array}{l}\text { Set } \\
\text { length } \\
\text { (kb) }\end{array}$ & CdNS & CpNS & $\begin{array}{l}\mathrm{p}- \\
\text { value }\end{array}$ & $\begin{array}{l}\text { FDR } \\
\mathrm{a}\end{array}$ & Gene included ${ }^{b}$ \\
\hline $\begin{array}{l}\text { Neuroactive } \\
\text { ligand-receptor } \\
\text { interaction }\end{array}$ & 123 & 500 & 19.46 & 26.21 & $\begin{array}{l}5.79 \\
110^{-27}\end{array}$ & $\begin{array}{l}1.45 \\
10^{-24}\end{array}$ & 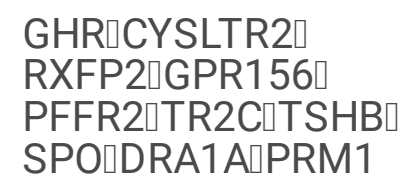 \\
\hline $\begin{array}{l}\text { Hematopoietic } \\
\text { cell lineage }\end{array}$ & 26 & 99 & 14.21 & 7.28 & $\begin{array}{l}3.67 \\
' 10^{-4}\end{array}$ & $\begin{array}{l}4.60 \\
' 10^{-2}\end{array}$ & 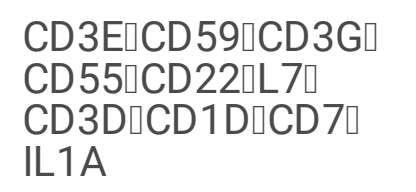 \\
\hline $\begin{array}{l}\text { Cytokine- } \\
\text { cytokine } \\
\text { receptor } \\
\text { interaction }\end{array}$ & 88 & 321 & 32.46 & 24.18 & $\begin{array}{l}1.61 \\
' 10^{-3}\end{array}$ & $\begin{array}{l}1.18 \\
' 10^{-1}\end{array}$ & 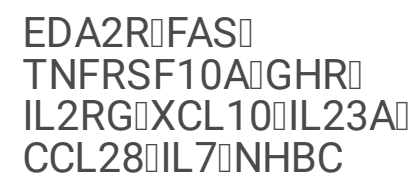 \\
\hline $\begin{array}{l}\text { Parkinson's } \\
\text { disease }\end{array}$ & 37 & 107 & 10.62 & 10.59 & $\begin{array}{l}2.33 \\
' 10^{-3}\end{array}$ & $\begin{array}{l}1.18 \\
' 10^{-1}\end{array}$ & 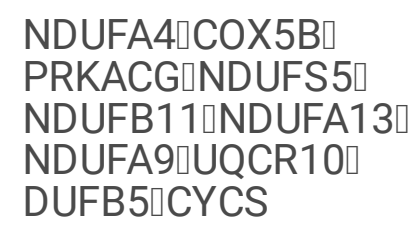 \\
\hline $\begin{array}{l}\text { Complement } \\
\text { and coagulation } \\
\text { cascades }\end{array}$ & 30 & 101 & 12.51 & 7.88 & $\begin{array}{l}2.35 \\
' 10^{-3}\end{array}$ & $\begin{array}{l}1.18 \\
' 10^{-1}\end{array}$ & 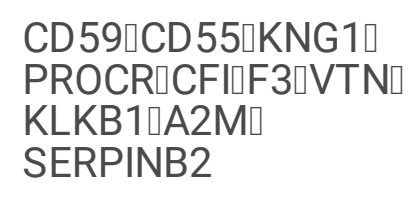 \\
\hline $\begin{array}{l}\text { Oxidative } \\
\text { phosphorylation }\end{array}$ & 35 & 104 & 10.86 & 10.36 & $\begin{array}{l}3.54 \\
' 10^{-3}\end{array}$ & $\begin{array}{l}1.48 \\
' 10^{-1}\end{array}$ & 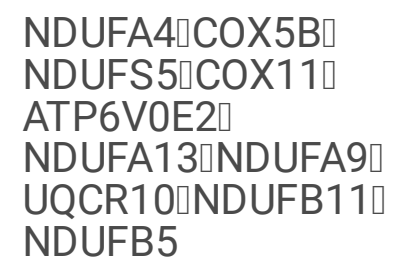 \\
\hline $\begin{array}{l}\text { Chemokine } \\
\text { signaling } \\
\text { pathway }\end{array}$ & 51 & 210 & 7.95 & 11.56 & $\begin{array}{l}4.24 \\
' 10^{-3}\end{array}$ & $\begin{array}{l}1.52 \\
' 10^{-1}\end{array}$ & 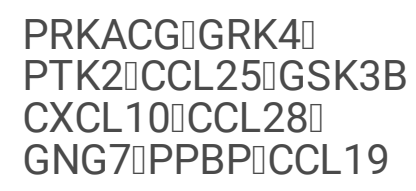 \\
\hline $\begin{array}{l}\text { Circadian } \\
\text { entrainment }\end{array}$ & 34 & 241 & 4.23 & 5.49 & $\begin{array}{l}6.70 \\
' 10^{-3}\end{array}$ & $\begin{array}{l}1.87 \\
' 10^{-1}\end{array}$ & 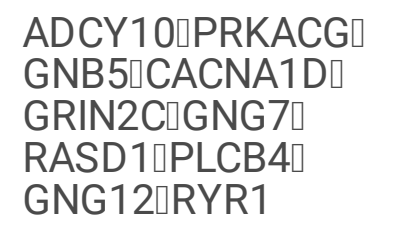 \\
\hline $\begin{array}{l}\text { Base excision } \\
\text { repair }^{b}\end{array}$ & 15 & 50 & 5.224 .23 & 5.42 & $\begin{array}{l}5.79 \\
' 10^{-3}\end{array}$ & $\begin{array}{l}1.82 \\
' 10^{-1}\end{array}$ & 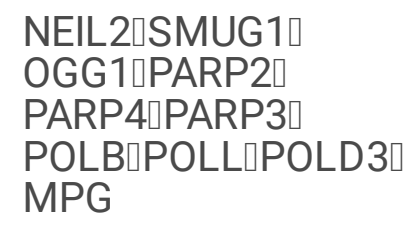 \\
\hline
\end{tabular}

Note. ${ }^{\text {a }}$ Pathways with FDR $<0.2$ are listed. 
${ }^{b}$ In each pathway, the top 10 genes with the highest $\mathrm{dN} / \mathrm{dS}$ or $\mathrm{pN} / \mathrm{pS}$ are listed.

Table 3. Differentially evolutionary pathways in genes heterochronically expressed in the brain of human and macaque

\begin{tabular}{|c|c|c|c|c|c|c|c|}
\hline Pathway & $\begin{array}{l}\text { Gene } \\
\text { number }\end{array}$ & $\begin{array}{l}\text { Set } \\
\text { length } \\
(\mathrm{kb})\end{array}$ & CdNS & CpNS & $\begin{array}{l}\mathrm{p}- \\
\text { value }\end{array}$ & $\begin{array}{l}\text { FDR } \\
\mathrm{a}\end{array}$ & Gene included $^{\mathrm{b}}$ \\
\hline $\begin{array}{l}\text { Cytokine-cytokine } \\
\text { receptor interaction }\end{array}$ & 12 & 43 & 4.99 & 2.27 & $\begin{array}{l}8.67 \\
10^{-14}\end{array}$ & $\begin{array}{l}3.81 \\
10^{-12}\end{array}$ & 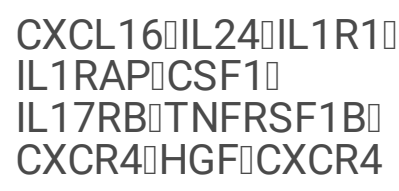 \\
\hline $\begin{array}{l}\text { Complement and } \\
\text { coagulation } \\
\text { cascades }\end{array}$ & 10 & 43 & 2.97 & 1.96 & $\begin{array}{l}6.80 \\
10^{-4}\end{array}$ & $\begin{array}{l}1.50 \\
10^{-2}\end{array}$ & 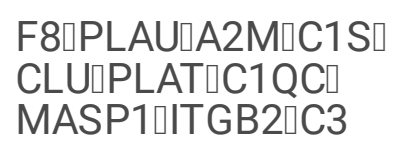 \\
\hline $\begin{array}{l}\text { Protein processing } \\
\text { in endoplasmic } \\
\text { reticulum }\end{array}$ & 11 & 43 & 0.99 & 2.21 & $\begin{array}{l}1.90 \\
10^{-3}\end{array}$ & $\begin{array}{l}2.79 \\
10^{-2}\end{array}$ & 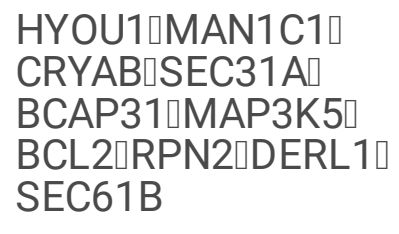 \\
\hline $\begin{array}{l}\text { Fluid shear stress } \\
\text { and atherosclerosis }\end{array}$ & 11 & 46 & 2.50 & 1.98 & $\begin{array}{l}8.04 \\
10^{-3}\end{array}$ & $\begin{array}{l}8.84 \\
10^{-2}\end{array}$ & 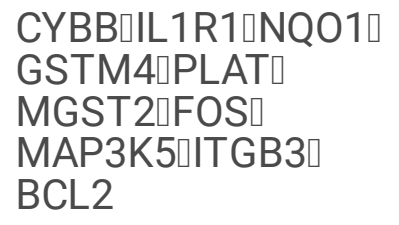 \\
\hline
\end{tabular}

Note. ${ }^{a}$ Pathways with FDR $<0.2$ are listed.

${ }^{b}$ In each pathway, the top 10 genes with the highest $d N / d S$ or $p N / p S$ are listed.

\section{Figures}




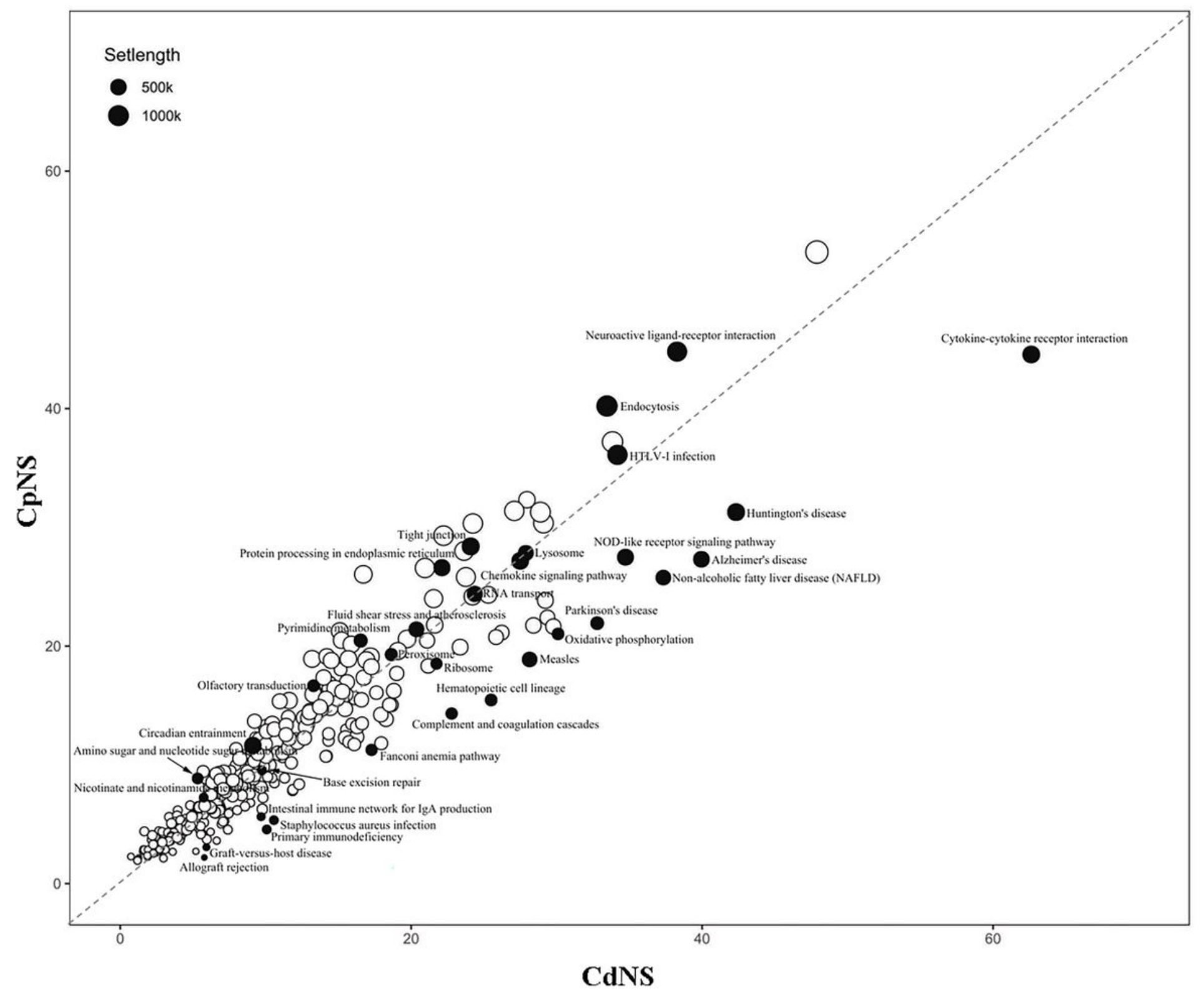

\section{Figure 1}

Distribution of pathways on the CdNS and CpNS plane. (A) 313 pathways are arranged at point according to the N/S ratios. The level of significance is indicated by the color range (dark blue, significant; light blue, not significant). The point size indicates the length of the set. The points of 32 pathways are strengthened. (B) Scatter plot of bin where 32 differential pathways are located. Grey background represents all random pathways in each bin. Outlier pathways with significant differences are shown in black outline. 


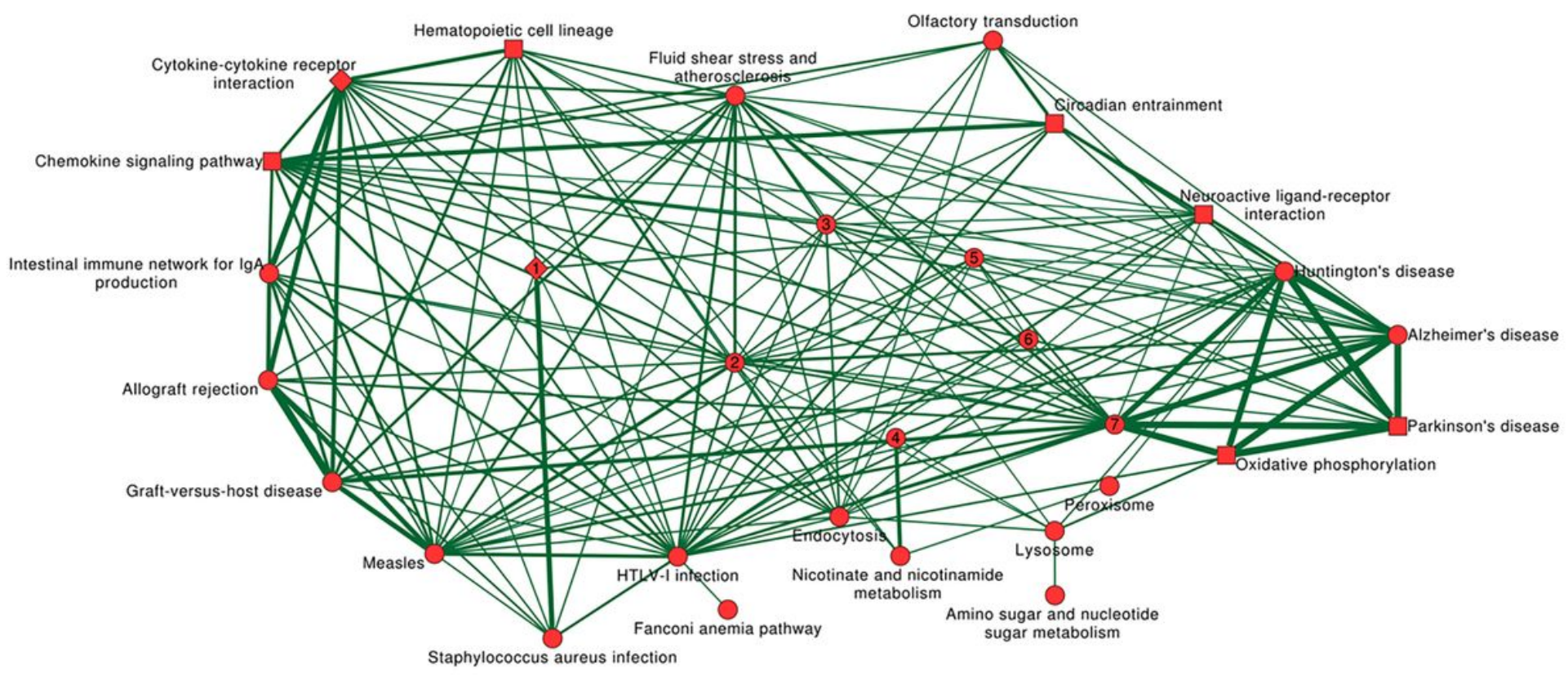

Figure 2

Network of evolutionarily different pathways in the brain of humans and macaques. The diamond points are the common pathways of the heterotopic and heterochronic results, the rectangle points are the pathways in the heterotopic results, the triangle points are the pathways in the heterochronic results. The width of the edge is proportional to the overlap significance of the corresponding pathway pair. The nodes with numbers represent the following meanings: 1 , Complement and coagulation cascades; 2 , NOD-like receptor signaling pathway; 3 , Tight junction; 4, Pyrimidine metabolism; 5 , Protein processing in endoplasmic reticulum; 6, RNA transport; 7, Non-alcoholic fatty liver disease (NAFLD). 


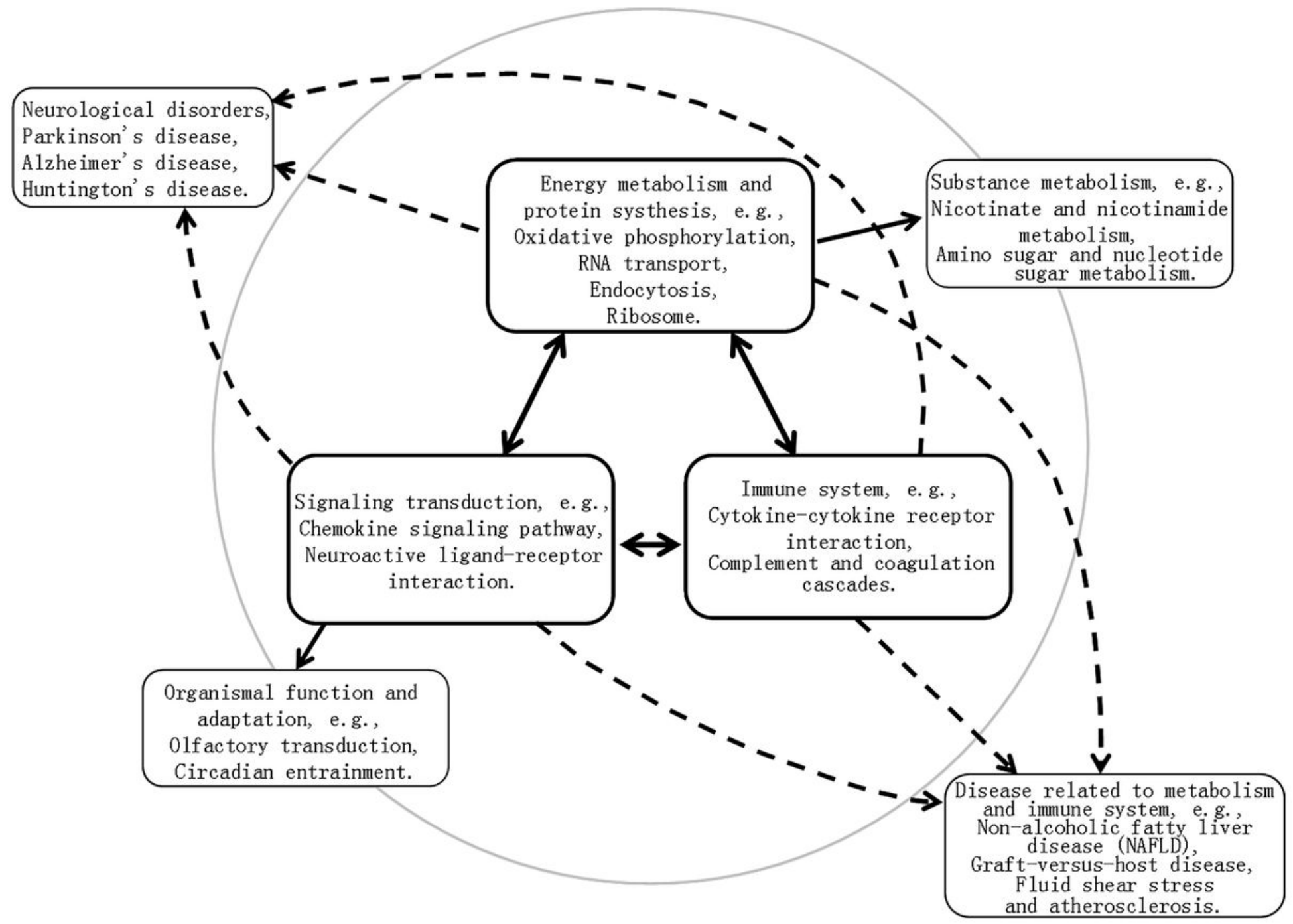

Figure 3

Major pathways potentially related to the evolution of the human nervous system. The evolution of human nervous system is complicated, with number of pathways involved. Among the pathways, there are those related to fundamental functions like signaling transduction, immune system, energy metabolism or protein synthesis, some may be related to neurological disorders or other diseases.

\section{Supplementary Files}

This is a list of supplementary files associated with this preprint. Click to download.

- SupplementaryFigures.ppt

- SupplementaryMaterials.doc

- Supplementarydatasets.xls 